\title{
PLANO NACIONAL DE SEGURANÇA DE BARRAGENS: UMA ANÁLISE SOBRE A APLICABILIDADE DA POLÍTICA NACIONAL DE SEGURANÇA NAS BARRAGENS DE CONTENÇÃO DE REJEITOS NO BRASIL
}

\author{
AVELAR DE ARAUJO, ANELISE \\ Engenheira Civil \\ UniAtenas \\ Minas Gerais; Brasil \\ avelarengc@gmail.com
}

\author{
DIAS RUAS, MATHEUS \\ Engenheiro Civil \\ UniAtenas \\ Minas Gerais; Brasil \\ ruas91@gmail.com
}

\author{
CRUVINEL LISBOA, IGOR ALEXANDRE \\ Engenheiro Civil \\ UniAtenas \\ Minas Gerais; Brasil \\ igorclisboa@outlook.com
}

\section{RESUMO}

A engenharia civil brasileira está em alerta em relação à segurança das barragens no país. Apesar do assunto ter se destacado nos últimos quatro anos devido a dois grandes rompimentos envolvendo barragens de terra, é de dois mil e dez a Lei ${ }^{\circ} 12.334$ que criou a Política Nacional de Segurança de Barragens (PNSB). Nela ficou estabelecida que todas as estruturas destinadas ao acúmulo de água para qualquer fim; à contenção temporária ou final de resíduos de rejeitos e à concentração de resíduo industrial no país, deveriam estar inseridas na PNSB. Contudo, o último Relatório de Segurança de Barragens-2017 mostra que das 790 barragens de rejeitos cadastradas no Sistema Nacional de Informações sobre Segurança de Barragens (SNISB), apenas 210 tem o Plano de Ação de Emergência - PAE. Informações mais recentes da Agência Nacional de Mineração (ANM), apontam que até o rompimento da barragem de Brumadinho-MG, o Brasil dispunha apenas de 34 funcionários atuando na fiscalização das barragens de rejeitos cadastradas em todo país. Este trabalho tem como objetivo, analisar e enumerar os principais motivos que contribuem e dificultam a efetiva execução da lei. Para realização do trabalho, foram feitas pesquisas bibliográficas e análises dos dados no SNISB, relacionando-os aos recentes rompimentos e o processo fiscalizatório. Concluiu-se então, que as principais causas que interferem à execução da Política Nacional de Segurança de Barragens são: falta de corpo técnico especializado; o número de agentes fiscalizadores é insuficiente; a possibilidade de os empreendedores contratar seus próprios agentes fiscalizadores e a necessidade de elevadas produções de minérios para suprir a demanda do mercado. Palavras-chave: Barragens, Lei $n^{\circ}$ 12.334/2010, Segurança de Barragens.

\begin{abstract}
Brazilian civil engineering is on the alert about dam safety in the country. Although the issue has stood out in the last four years due to two major disruptions involving earth dams, it is two thousand and ten, Law No. 12,334 that created the National Dam Safety Policy (PNSB). It has been established that all structures intended for the accumulation of water for any purpose; the temporary or final containment of tailings waste and the concentration of industrial waste in the country should be included in the PNSB. However, the latest Dam Safety Report-2017 shows that of the 790 tailings dams registered in the National Dam Safety Information System (SNISB), only 210 have the Emergency Action Plan PAE. Latest information from the National Mining Agency (ANM), indicates that until the Brumadinho-MG dam rupture, Brazil had only 34 employees working to inspect the tailings dams registered throughout the country. This paper aims to analyze and list the main reasons that contribute and hinder the effective enforcement of the law. To carry out the work, bibliographic research and data analysis were performed in SNISB, relating them to recent disruptions and the inspection process. It was concluded, then, that the main causes that interfere with the execution of the National Dam Safety Policy are: lack of specialized technical staff; the number of enforcement agents is insufficient; the possibility for entrepreneurs to hire their own supervisory agents and the need for high ore production to meet market demand.
\end{abstract}

Keywords: abstract, recommendations, standardization. 


\section{INTRODUÇÃO}

Em decorrência do aumento no número de acidentes envolvendo as barragens brasileiras, o país encontra-se num cenário grave no que diz respeito à segurança das barreiras artificiais, construídas com o intuito de reter ou armazenar enormes volumes de água e resíduos. As obras especiais de engenharia civil devem cumprir importantes e rigorosos critérios de segurança para garantir seu correto desempenho estrutural desde a fase de projeto, execução e utilização.

Em 2010 foi estabelecida a Lei 12.334/2010 que criou o SNISB (Sistema Nacional de Informações Sobre Segurança de Barragens) e a PNSB (Política Nacional de Segurança de Barragens) que exige dos empreendedores do ramo, a inserção de condições mínimas necessárias para a segurança da barragem e encaminhamento aos órgãos fiscalizadores de todas as informações referentes a qualquer mudança estrutural e de funcionamento da mesma.

Das vinte e quatro mil barragens hoje cadastradas no SNIB, pouco mais de cinco mil obedecem aos critérios do PNSB, em vista disso, elas dispõem do direito de serem fiscalizadas regularmente pelos agentes fiscalizadores da esfera pública. Contudo, não são todas que passam por essa fiscalização com a periodicidade exigida. Vários são os fatores que dificultam esse trabalho como, por exemplo, número insuficiente de agentes; falta de um corpo técnico devidamente especializado; discrepância nos dados entre a Agência Nacional de Águas (ANA) e os órgãos fiscalizadores, entre outros.

A engenharia civil brasileira em conjunto com suas legislações, requisitos normativos e instrumentação técnica dispõe de totais condições de monitoramento efetivo dessas estruturas. Dessa forma, além da imprescindível consciência dos empreendedores em erguer obras seguras, eficientes e que respeitem o meio ambiente, o cumprimento do PNSB é essencial para assegurar que todas as exigências sejam de fato realizadas, e é nesse momento que entra o trabalho dos agentes fiscalizatórios.

\section{METODOLOGIA EXECUTIVA DA LEI No $12.334 / 2010$}

\subsection{BARRAGENS}

De acordo com o Instituto Brasileiro de Sustentabilidade (2019), barragem é uma obra da engenharia construída naturalmente ou artificialmente em um curso de água temporário ou permanente com a finalidade de conter, armazenar ou controlar volumes de água ou resíduos. As barragens podem ser de diversos tipos estruturais, isso dependerá da sua finalidade, aspectos geológicos do local onde será executada e do material que irá compor sua estrutura principal. Podendo ser barragens de terra, de enrocamento com face de concreto, de contraforte, em arco, de gravidade ou gravidade aliviada.

\subsection{INSERÇÃO DAS ESTRUTURAS NA POLÍTICA NACIONAL DE SEGURANÇA DE BARRAGENS}

Desde 2010, para uma barragem ser inserida na PNSB e devidamente fiscalizada dentro de todas as normativas da Lei 12.334, ela precisa estar enquadrada em alguns critérios desde sua etapa de projeto até o seu funcionamento ou desativação. Para estruturas já existentes, as exigências são as mesmas. Os critérios de inserção das barragens ao plano nacional de segurança, são:

Art. 1o Esta Lei estabelece a Política Nacional de Segurança de Barragens (PNSB) e cria o Sistema Nacional de Informações sobre Segurança de Barragens (SNISB).

Parágrafo único. Esta Lei aplica-se a barragens destinadas à acumulação de água para quaisquer usos, à disposição final ou temporária de rejeitos e à acumulação de resíduos industriais que apresentem pelo menos uma das seguintes características:

I- altura do maciço, contada do ponto mais baixo da fundação à crista, maior ou igual a $15 \mathrm{~m}$ (quinze metros);

II- capacidade total do reservatório maior ou igual a $3.000 .000 \mathrm{~m}^{3}$ (três milhões de metros cúbicos);

III- reservatório que contenha resíduos perigosos conforme normas técnicas aplicáveis;

IV- categoria de dano potencial associado, médio ou alto, em termos econômicos, sociais, ambientais ou de perda de vidas humanas, conforme definido no art. 6o. 
Os dados técnicos da estrutura, como altura, capacidade do reservatório e tipo de resíduos contidos na barragem devem ser disponibilizados e inseridos no SNISB pelo empreendedor e exigidos pelo órgão fiscalizador. Já a classificação das estruturas quanto ao dano potencial associado e categoria de risco, é feita pelos agentes fiscalizadores, a partir de critérios criados pelo Conselho Nacional de Recursos Hídricos (CNRH).

Após a análise do projeto ou da estrutura já existente, se ela estiver dentro das características mínimas apresentadas anteriormente será feita uma classificação da barragem. Essa classificação será feita a partir de três parâmetros, sendo eles, categoria de risco, dano potencial associado e volume. O Conselho Nacional de Recursos Hídricos foi o órgão responsável pela elaboração desses parâmetros, atendendo ao art. $7^{\circ}$ da Lei 12.334/2010. Na categoria de risco alguns critérios são analisados, como: características técnicas (CT) que são os dados da própria estrutura, dados esses que podem ter potencial de influenciar no acontecimento de algum acidente; estado de conservação (EC) que engloba a integridade estrutural, operacional, e manutenção da barragem e por fim, o Plano de Segurança da Barragem (PSB) com suas exigências mínimas descritas na figura a seguir.

1. Identificação do empreendedor.

2. Dados técnicos referentes à implantação do empreendimento, inclusive, no caso de empreendimentos construídos após a promulgação da Lei, do projeto como construído, bem como aqueles necessários para a operação e manutenção da barragem.

\section{Estrutura organizacional e qualificação técnica dos profissionais} da equipe de segurança da barragem.

4. Guia de Inspeções e outros Manuais de procedimentos dos roteiros de inspeções de segurança e de monitoramento e relatórios de segurança da barragem.

5. Regra operacional dos dispositivos de descarga da barragem.

6. Indicação da área do entorno das instalações e seus respectivos acessos, a serem resguardados de quaisquer usos ou ocupações permanentes, exceto aqueles indispensáveis à manutenção e à operação da barragem.

\section{Relatórios das Inspeções de Segurança.}

8. Revisões Periódicas de Segurança.

9. Plano de Ação de Emergência (PAE), quando exigido.

Figura 1: Plano de Segurança da Barragem

Fonte: Manual do empreendedor sobre segurança de barragens (2016, p. 18)

O volume do reservatório é usado como critério para a classificação quanto ao Dano Potencial Associado (DPA) que é avaliado de acordo com as consequências que podem vir a acontecer por vazamentos, infiltrações no solo, funcionamentos inadequados da barragem, rompimentos diversos, e todos independentes de probabilidade de 
ocorrência. Impactos socioeconômicos e ambientais, perda de vida animal, vegetal e humana, são algumas das consequências analisadas.

Através dessas informações uma pontuação determinada pelo Conselho Nacional de Recursos Hídricos é atribuída a partir das características da barragem analisada. Esses pontos são somados por categoria e depois transferidos para a última tabela e colocada em seus respectivos lugares. Dessa forma as categorias de risco e dano potencial associada da estrutura serão classificadas em baixo, médio ou alto a partir dos limites no quadro a seguir.

Quadro 1: Classificação das barragens para acumulação de água

Fonte: Classificação de barragem quanto à categoria de risco a ao dano potencial associado (2013, p.6)

\begin{tabular}{|c|c|c|}
\hline \multicolumn{2}{|r|}{ II.1 - CATEGORIA DE RISCO } & \multirow[t]{2}{*}{ Pontos } \\
\hline 1 & Características Técnicas (CT) & \\
\hline 2 & Estado de Conservação (EC) com $\mathrm{g}=10^{*}$ & \\
\hline 3 & Plano de Segurança de Barragens (PS) & \\
\hline \multicolumn{2}{|c|}{ PONTUAÇÃO TOTAL (CRI) = CT + EC + PS } & \\
\hline \multirow{5}{*}{ 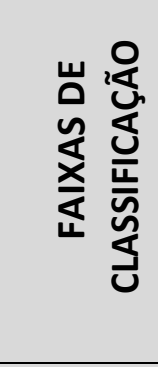 } & CATEGORIA DE RISCO & CRI \\
\hline & ALTO & $>=60$ ou $\mathrm{EC}=8\left({ }^{*}\right)$ \\
\hline & MÉDIO & 35 a 60 \\
\hline & BAIXO & $<=35$ \\
\hline & \multicolumn{2}{|c|}{$\begin{array}{l}\text { (*)Pontuação (8) em qualquer coluna de Estado de Conservação (EC) } \\
\text { implica automaticamente CATEGORIA DE RISCO ALTA e necessidade de } \\
\text { providencias imediatas pelo responsável da barragem. }\end{array}$} \\
\hline \multirow{2}{*}{\multicolumn{2}{|c|}{$\begin{array}{l}\text { II.2 - DANO POTENCIAL ASSOCIADO } \\
\text { DANO POTENCIAL ASSOCIADO (DPA) }\end{array}$}} & Pontos \\
\hline & & \\
\hline \multirow{4}{*}{ 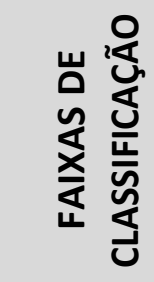 } & DANO POTENCIAL ASSOCIADO & DPA \\
\hline & ALTO & $>=16$ \\
\hline & MÉDIO & $10<\mathrm{DP}<16$ \\
\hline & BAIXO & $<=10$ \\
\hline \multicolumn{3}{|c|}{ RESULTADO FINAL DA AVALIAÇÃO: } \\
\hline \multirow{2}{*}{\multicolumn{2}{|c|}{\begin{tabular}{|l|} 
CATEGORIA DE RISCO \\
DANO POTENCIAL ASSOCIADO
\end{tabular}}} & \\
\hline & & \\
\hline
\end{tabular}

Vale ressaltar que essa forma de classificação é feita a partir de dados gerais para a formulação da tabela final, gerando assim apenas condições de avaliar quais barragens poderiam ser menos seguras. Com base nela, a Agência Nacional de Águas (ANA) elaborou uma Matriz de Categoria de Risco e dano Potencial Associado utilizando a ISO/IEC 31010:2009 (ABNT,2009), relacionando de formas qualitativas ou semiquantitativas a propabilidade de algo acontecer e suas consequencias, gerando assim niveis de risco ou classificação de risco. Dessa forma, a classificação das barragens em níveis de risco de A a E é resultado da relação entre o dano potencial e a categoria de risco de uma determinada estrutura, conforme o quadro abaixo. Isso viabiliza uma análise muito mais contundente e precisa.

Quadro 2: Quadro para Classificação de Barragem

Fonte: Classificação de barragem quanto à categoria de risco a ao dano potencial associado $(2013$, p.6)

\begin{tabular}{|c|c|c|c|}
\hline \multirow{2}{*}{$\begin{array}{c}\text { CATEGORIA } \\
\text { DE RISCO }\end{array}$} & \multicolumn{3}{|c|}{ DANO POTENCIAL ASSOCIADO } \\
\cline { 2 - 4 } & ALTO & MÉDIO & BAIXO \\
\hline ALTO & A & B & C \\
\hline MÉDIO & A & C & D \\
\hline BAIXO & A & D & E \\
\hline
\end{tabular}


O PSB - Plano de Segurança de Barragens - é o instrumento que deverá ser utilizado obrigatoriamente pelo empreendedor para direcionar as medidas de segurança necessárias para sua barragem. A elaboração do PSB para estruturas já construídas deverá estar pronta no prazo máximo de um ano depois da Revisão Periódica de Segurança de Barragens (RPSB), o tempo de elaboração dessa revisão depende do número de barragens do empreendedor e está especificado na Resolução da ANA n 91/2012. Para novas barragens, é exigida a finalização do PSB antes da operação da barragem ser iniciada.

Tanto a Revisão Periódica quanto o Plano de Segurança de Barragens devem ser elaborados por algum profissional técnico devidamente registrado no Conselho Regional de Engenharia e Agronomia (CREA), e com atuação autorizada para projetar, operar, construir, elaborar e fiscalizar manutenções de barragens de terra ou concreto. As possíveis atualizações no PSB tornam-se necessárias em consequência aos resultados obtidos por fiscalizações e as revisões periódicas.

\subsection{CORPO TÉCNICO}

Informações mais recentes da Agência Nacional de Mineração (ANM) apontam que até o rompimento da barragem de Brumadinho-MG, o Brasil dispunha apenas de 34 funcionários atuando na fiscalização de pelo menos 790 barragens de contenção de minério em todo país. No Relatório de Segurança de Barragem (RSB-2017) aponta que das 19 barragens no Brasil classificadas como de alto risco, 12 localizam-se em Minas Gerais. Este é o estado que mais possui esse tipo de estrutura, a figura abaixo retirada do último RSB-2017, mostrou a existência de no mínimo 357 barragens no estado destinadas a esse fim.

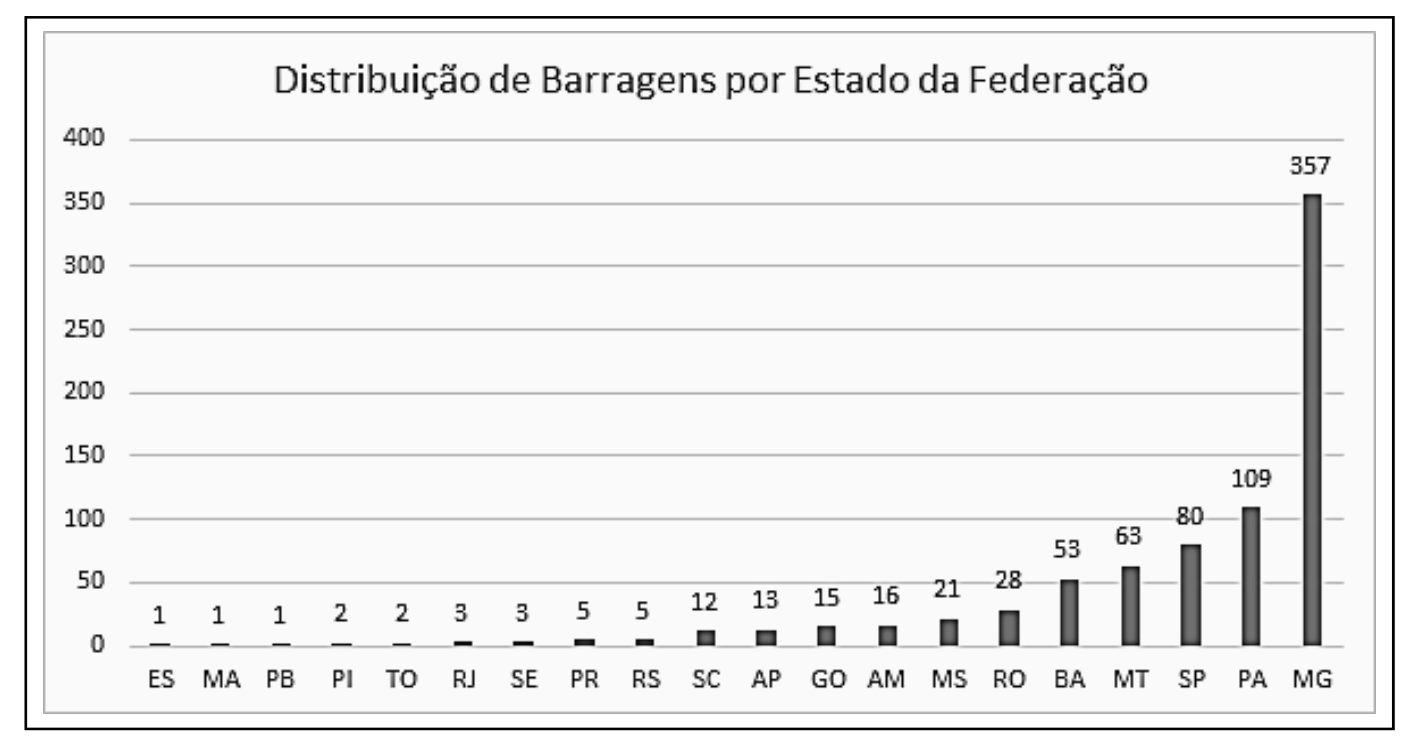

Figura 2: Distribuição de barragens por estado da federação

Fonte: Relatório de Segurança de Barragens (2017)

A composição da equipe técnica de fiscalização é normatizada pelo Manual de Políticas e Práticas de Segurança de Barragens para Entidade Fiscalizadora, nela fica determinada a indispensabilidade de uma quantidade mínima de fiscais com dedicação exclusiva em relação ao número de barragens cadastradas em cada órgão. Até 30 barragens, seria necessários 2 técnicos; até 100 barragens, uma equipe de 2 a 5 técnicos; até 300 barragens o número estimado passaria de 6 a 10 técnicos; até 1000 barragens necessitariam de no mínimo 10 a 20 técnicos; acima de 1000 barragens a exigência passa a ser de mais de 20 técnicos.

Sendo assim, na teoria, a ANM tem corpo técnico suficiente segundo as exigências do Manual de Políticas e Práticas de Segurança de Barragens para Entidade Fiscalizadora. No entanto, o Manual especifica a necessidade de os fiscais exercerem suas funções de forma exclusiva, coisa que não acontece. Além das fiscalizações, os servidores atuam também em liberações de outorgas e licenciamentos. 
Segundo as informações do RSB (2017), em torno de 55\% das entidades fiscalizadoras não contam com uma equipe com atribuições exclusivas e formais para atuar na fiscalização das barragens. E mesmo os servidores que dispõe de cargos com funções exclusivas, realizam outras atividades que fogem da exclusividade do cargo. A ANA e a ANM, entende que na falta de corpo técnico exclusivo nas agências estatais, os empreendedores estão autorizados a passar as informações técnicas e de estabilidade das estruturas através de laudos emitidos por empresas contratadas pelos próprios proprietários. Segundo o relatório do Tribunal de Contas da União de 2018, nenhum concurso para aumento do quadro de funcionários foi estabelecido desde 2009.

Para a elaboração do relatório de segurança de barragens é necessário que os órgãos fiscalizadores, tanto das esferas estaduais quantos federais, enviem os dados de todas as barragens cadastradas em seus sistemas. Segundo o Sistema Nacional de Informações de Segurança de Barragens, no Brasil, existem 43 órgãos com autonomia para atuar nas fiscalizações dessas estruturas. Entretanto, apenas 31 entidades fiscalizadoras atuam diretamente.

O RSB (2017) aponta que essa redução se deve ao fato de alguns órgãos terem alegado não possuir barragens cadastradas em seu sistema ou não disponibilizarem de informações recentes e outros afirmaram que seus cadastros foram desativados por problemas operacionais em seu sistema.

\subsection{INVESTIMENTOS ESTATAIS}

Partindo da obrigatoriedade e das exigências mínimas da Lei 12.334, as agências fiscalizadoras tanto estaduais quanto federais devem possuir investimentos governamentais apropriados para execução correta da Lei. Mas não é isso que acontece. Em abril deste ano, dois meses após o crime ambiental ocorrido em Brumadinho, segundo o Tribunal de Contas da União, o governo federal decidiu pelo bloqueio de 15 milhões de reais da Agência Nacional de Mineração.

Segundo o governo de Michel Temer, a criação da Agência Nacional de Mineração no lugar do Departamento de Nacional de Produção Mineral em 2018, tinha como objetivo a maior independência do órgão e aumento dos valores orçamentários destinados à regulação e fiscalização nas barragens brasileiras. Com previsão de investimento em 2019 de 63 milhões de reais, o bloqueio das contas da agência pelo atual governo diminuirá o orçamento para 43 milhões de reais.

O último Relatório de Gestão da ANM (2017) aponta que os gastos foram fechados em 40 milhões de reais, e a maior parte desse orçamento foi destinada para operações administrativas e resumidamente para operações fiscalizatórias. No mesmo relatório, foi mencionada a dificuldade da agência de conseguir planejar e direcionar o orçamento para todas as suas operações, estando até com suas operações básicas de funcionamento no limite.

Um dos motivos apontados seria a liberação de verba não sendo feita de uma só vez, dessa forma, a elaboração de um planejamento seria prejudicada ou em determinados casos inexistente. Fazendo uma análise dos últimos relatórios de gestão, em torno de $80 \%$ por cento do orçamento fica em despesas e administrativas e apenas $20 \%$ para fiscalizações, capacitações e aumento do quadro de servidores exclusivos para atuar in loco. Dessa forma, a figura a seguir retrata a diminuição no número de fiscalizações nos últimos dez anos.

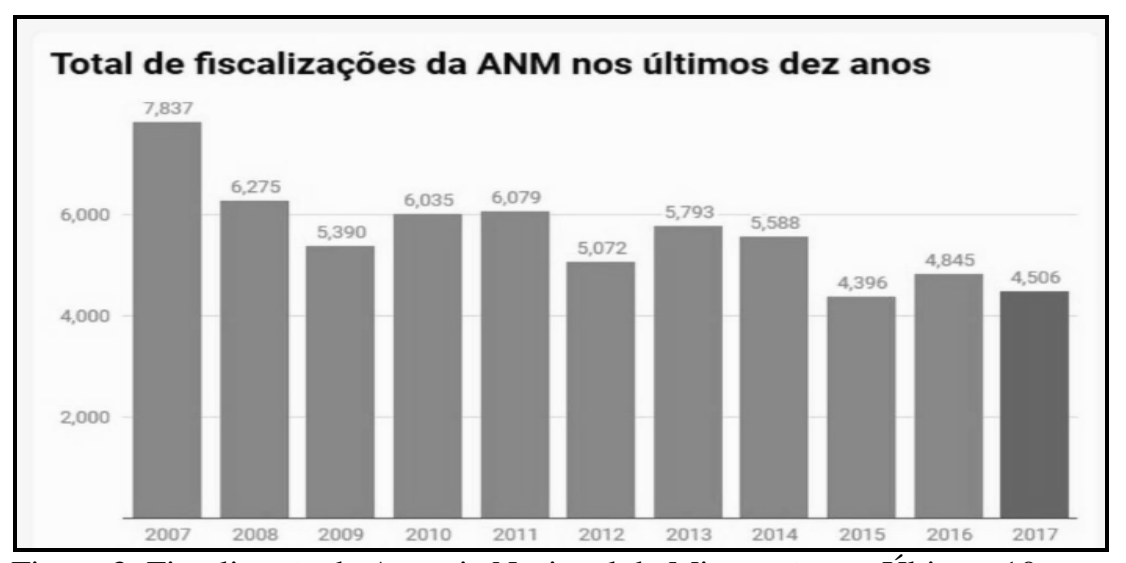

Figura 3: Fiscalização da Agencia Nacional de Mineração nos Últimos 10 anos

Fonte: Relatório de gestão da ANM (2017, p.69) 
Existem duas formas de fiscalização determinadas pela Agência Nacional de Mineração (ANM). Uma delas é a análise documental das barragens cadastradas, exigidas pela lei aos proprietários das estruturas e a outra seria a visita técnica do agente. O Relatório de Gestão (2017) da agência mostra que no Estado de Minas Gerais onde a concentração de barragens de atividade minerária representa 52\% do total da atividade no país, das 357 barragens cadastradas no SNISB, apenas 74 tiveram vistorias presenciais.

\section{PLANO DE AÇÃO DE EMERGÊNCIA-PAE EM BARRAGENS DE REJEITOS}

O PAE é estabelecido no art. 12 da Lei 12334/2010:

Art. 12. O PAE estabelecerá as ações a serem executadas pelo empreendedor da barragem em caso de situação de emergência, bem como identificará os agentes a serem notificados dessa ocorrência, devendo contemplar, pelo menos:

I- identificação e análise das possíveis situações de emergência;

II- procedimentos para identificação e notificação de mau funcionamento ou de condições potenciais de ruptura da barragem;

III- procedimentos preventivos e corretivos a serem adotados em situações de emergência, com indicação do responsável pela ação;

IV- estratégia e meio de divulgação e alerta para as comunidades potencialmente afetadas em situação de emergência.

Parágrafo único. O PAE deve estar disponível no empreendimento e nas prefeituras envolvidas, bem como ser encaminhado às autoridades competentes e aos organismos de defesa civil.

Apesar do Plano de Ação de Emergência ser um documento de caráter técnico, a redação desse documento deverá ser feita de forma que possibilite uma compreensão clara e acessível para o leitor. A criação do PAE é competência do empreendedor, que deverá contratar empresas de engenharia ou engenheiros especialistas em segurança de barragens. $\mathrm{O}$ principal objetivo da elaboração do Plano é poder evitar ou diminuir as consequências de um possível rompimento, preservando as comunidades e propriedades a jusante da barragem, juntamente com todo cenário ambiental local.

A partir das exigências do art. $^{\circ}$ 12, o PAE é um documento que estabelece a prevenção de situações de emergência levando-se em conta a garantia às informações técnicas, de monitoramento e execução prestadas pelo próprio empreendedor juntamente com as medidas que deveram ser tomadas em cenários de rompimento das barragens. Além disso, espera-se a inclusão de uma estratégia de divulgação do Plano e um respectivo treinamento tanto para o quadro de trabalhadores do complexo de barragens quanto para as comunidades ao redor.

Dentro do Plano de Ação Emergencial de Barragem de Minério (PAEBM) ainda é exigido segundo a portaria $\mathrm{n}^{\circ}$ 70.389/2017: a definição dos agentes que deverão ser notificados em caso de ocorrências, é obrigatório que o documento possua uma capa de cor vermelha para facilitar a identificação nos casos emergenciais, deve possuir as análises dos panoramas de inundação com todos os seus mapas, deve ser elaborado e definido a Zona de Autosalvamento (ZAS) que compreende em áreas a jusante da barragem que não dispõe de tempo adequado para que chegue salvamento por parte do empreendedor e nem pelas autoridades competentes e por fim, é estabelecido que cópias do Plano de Ação Emergencial das Barragens de Mineração estejam disponíveis nas Prefeituras e na Defesa Civil municipal e estadual.

Na mesma portaria $\mathrm{n}^{\circ} 70.389 / 2017$, é determinado os Níveis de Emergência da seguinte forma:

I-Nível 1 - Quando detectada anomalia que resulte na pontuação máxima de 10 (dez) pontos em qualquer coluna do Quadro 3 - Matriz de Classificação Quanto à Categoria de Risco (1.2 - Estado de Conservação), do Anexo V, ou seja, quando iniciada uma ISE e para qualquer outra situação com potencial comprometimento de segurança da estrutura;

II-Nível 2 - Quando o resultado das ações adotadas na anomalia referida no inciso I for classificado como "não controlado", de acordo com a definição do $\S 1^{\circ}$ do art. 27 desta Portaria; ou

III-Nível 3 - A ruptura é iminente ou está ocorrendo. 
O nível 1 é a classificação dada a primeira intercorrência ou anomalia estrutural perceptíveis com base nas análises feitas a partir do quadro 3 do anexo V da Resolução.

O Nível 2 é acionado quando as ações feitas para o controle dos problemas à Nível 1 não foram suficientes; e o Nível 3 é atingido a partir do momento em que uma ruptura já está em andamento ou em iminência de acontecer, pois nenhuma das medidas anteriores foram suficientes para evitar o dano.

Pela Lei 12.334/10, a necessidade da existência do Plano de Ação é obrigatória apenas para estruturas classificadas com alto dano potencial associado. Todas às outras barragens ficam a critério do órgão fiscalizador de considerar a necessidade de tal elaboração em relação aos seus respectivos danos potenciais associados e categoria de risco. A mesma Resolução declara que de 5 em 5 anos, as barragens devem ser avaliadas pelos órgãos fiscalizadores para novas classificações.

É expresso no art. $4^{\circ}$, parágrafo 3; art. 5, parágrafo 4, que não sendo possível a fiscalização in loco por um agente fiscalizador, é validado os dados fornecidos pelo próprio proprietário da barragem. Caso não seja apresentado nenhum dado, o órgão deve considerar as maiores classificações para todos os critérios, seja para dano potencial associado e/ou categoria de risco. Em relação às barragens de mineração, essas informações devem ser cadastradas no sistema do Relatório Anual de Lavra.

Em relação à mineração, existem mais de um órgão que podem exigir a elaboração do PAE. Tanto o órgão licenciador quanto a Agência Nacional de Mineração estão autorizados a isso, utilizando apenas o critério de enquadramento de dano potencial associado e categoria de risco da estrutura analisada.

Segundo o mais recente Relatório de Segurança de Barragens (2017), das 787 barragens de rejeitos existentes no Brasil, apenas 210 já tinham o Plano de Ação de Emergência elaborado. E do total de mais de 24 mil barragens existentes, apenas 765 tem um Plano de Ação de Emergência.

\section{PRODUÇÃO MINERÁRIA X ROMPIMENTO DE BARRAGENS}

Não é coincidência que os maiores, mais desastrosos e reincidentes rompimentos envolvendo barragens de rejeito de minérios encontram-se nas maiores potências de produção de minério do mundo. Dados obtidos através da UNCTAD (Conferência das Nações Unidas para o Comércio e o Desenvolvimento) e da U.S. Geological Survey, em 2011 o Brasil ocupou a terceira posição em produção (em toneladas) mundial de minério de ferro, atrás apenas da China e Austrália. Ainda dentro desse estudo, no Brasil, 67\% da produção está presente em Minas Gerais, 29,3\% no Pará e 3,7\% nos demais estados.

O Brasil é considerado um dos maiores produtores e exportadores de minério do mundo. Levando em consideração os dados do ano de 2015 do Centro de Comércio Internacional (ITC), de 2003 a 2013 as importações mundiais da mineração passaram de 38 bilhões de dólares para 277 bilhões. Só o Brasil foi responsável por mais de 14\% das exportações minerarias mundiais. Nesse mesmo intervalo de tempo, levando em consideração todos os produtos de exportação do país, a mineração passou a contribuir de 5\% para 14,5\% de todo esse mercado. Desse total de exportação, o minério de ferro foi responsável por $92,6 \%$ da cadeia produtiva.

Os relatórios do Banco Mundial (2015) mostram o quanto à atividade de extração mineral é oscilatória, principalmente do minério de ferro. Em janeiro de 2003 o preço desse recurso natural atingia um valor de 32 dólares a tonelada chegando a 196 dólares em abril de 2008. De 2011 em diante os valores por toneladas passaram por muitas quedas, sendo que em 2015 esse valor passou a ser de 53 dólares por tonelada.

Sendo assim, em 2009 Davies e Martin conseguiram fazer uma relação entre a variação financeira do preço do minério de cobre com os casos de rompimento de barragens após o início das quedas nos preços da exportação de minério. Essa relação foi baseada na valorização do metal desde o ano de 1965 até 2015 , em períodos que estivesse acima da taxa de inflação, correlacionando nos mesmos períodos os números de incidentes com barragens de rejeito. A escolha pela análise da exploração de cobre foi feita pela grande presença do minério nos resíduos das barragens que sofreram rompimentos. A figura a seguir apresenta essa relação. 


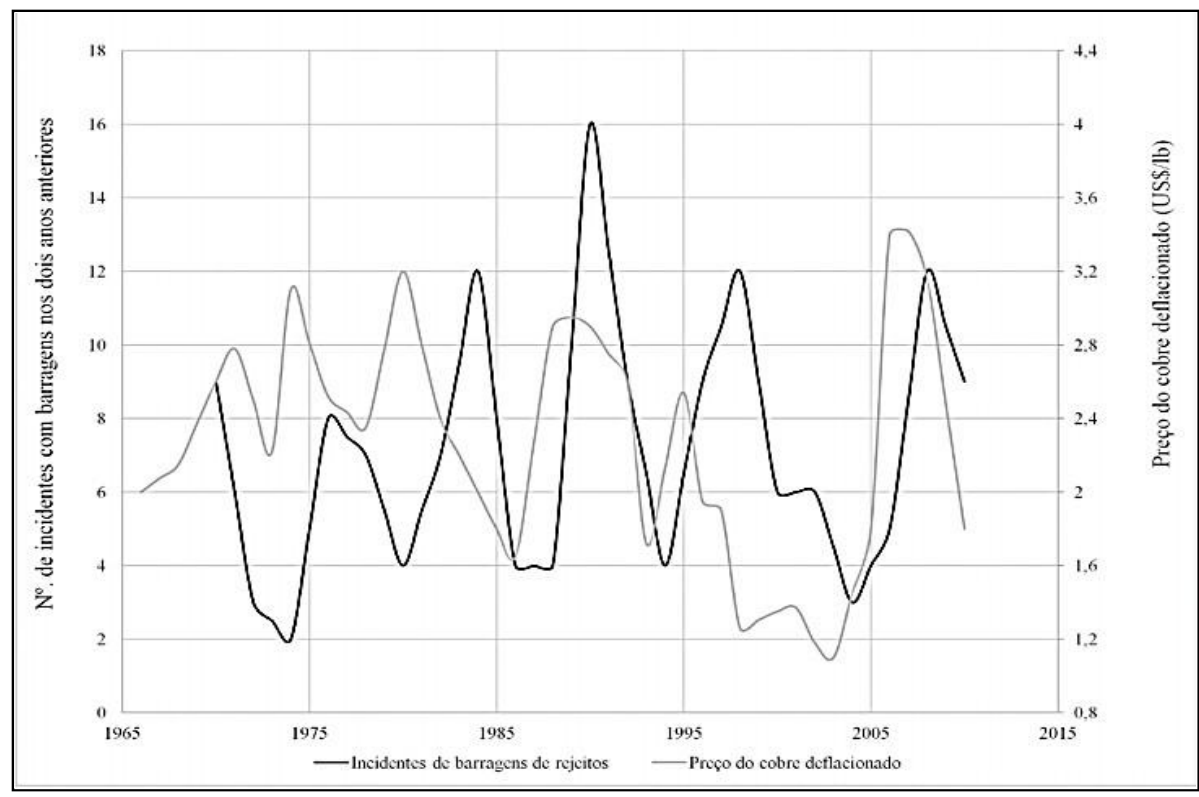

Figura 4: Preço do Minério e Rompimentos de Barragens de Rejeito

Fonte: Davies e Martin (2009,13th International Conference on Tailings and Mine Waste)

Para os autores, essa relação está diretamente ligada na pressão das empresas em conseguir licenciamento para funcionamento e exploração nos períodos em que os preços estão elevados; a utilização de tecnologias impróprias juntamente com a instalação de novos projetos em localizações inadequadas; exigências imediatas às agências ambientais para aprovação dos licenciamentos, levando a análises com pouco grau de confiança em relação ao potencial real de riscos e impactos; necessidade de contratação de serviços de engenharia a qualquer custo devido à grande demanda de exploração e levando ao fechamento de contratos com valores elevados; aumento da intensidade de produção e/ou pressão em reduzir outros custos de todo o processo.

A Agência Nacional de Mineração (ANM) é a responsável pelo controle e procedimentos de monitoramento de barragens no Brasil e atuando de forma adicional e ao mesmo tempo, existe a Fundação Estadual de Meio Ambiente (FEAM). Em 2014 o Inventário de Barragens de Minas Gerais, apontou a barragem de Fundão em Mariana (colapsada em 2015) como estável e ainda mencionou a existência de 27 barragens que estariam com seus níveis de estabilidade sem garantia, sendo que duas delas já apresentavam sinais de instabilidades desde 2012.

\section{CONSIDERAÇÕES FINAIS}

A presente pesquisa mostra que a partir de todos os dados e informações colhidos até a elaboração da mesma, das 769 barragens cadastradas no Cadastro Nacional de Barragens de Mineração, apenas 425 estão inseridas na Política Nacional de Segurança de Barragens. Está inserida na PNSB apenas mostra que se conhece teoricamente as informações técnicas básicas dessas estruturas, isso não garante, por exemplo, que elas tenham o Plano de Ação de Emergência (PAE) devidamente elaborado. As 344 barragens de rejeitos restantes, não pertencem a PNSB, os motivos podem ser variados desde o não conhecimento básico de informações como capacidade de reservatório e altura da barragem até divergências de informações entre proprietários e o sistema de cadastro.

Evidenciou-se assim a necessidade de maiores e mais efetivos investimentos no processo fiscalizatório, levando em consideração o baixo número de agentes fiscalizadores para atender ao grande número de barragens de contenção de rejeitos no país; maior controle das informações e um sistema de cadastro mais rápido e efetivo, pois a discrepância nos números dos órgãos fiscalizadores é preocupante; consciência de classe por parte dos engenheiros em exigir dos conselhos de engenharia proteção ao profissional que se recusa a autorizar e executar obras tecnicamente inseguras e instáveis.

Por fim, garantir a segurança em termos socioeconômicos e ambientais, preservar a integridade e monitoramento das estruturas, comprometimento das empresas com a divulgação de relatórios com dados que condizem com a realidade em relação a segurança e estabilidade de suas estruturas, são fatores imprescindíveis para que a Lei 12.334/2010 seja 
implantada e executada. A falta de leis claras e objetivas para crimes ambientais provenientes da mineração, também é um gatilho para que as empresas não garantam a segurança de suas estruturas. Infelizmente o maior e mais grave problema, não é técnico e sim moral e ético, impulsionado pelo desejo de poder e ganho financeiro a qualquer custo.

\section{REFERÊNCIAS}

AGÊNCIA NACIONAL DE ÁGUAS. Manual do empreendedor sobre segurança de barragens: diretrizes para elaboração do plano de operação, manutenção e instrumentação de barragens. Vol.7. Disponível em:<http://www.snisb.gov.br/portal/snisb/downloads/volume-vii-diretrizes-para-a-elaboracao-do-plano-de-operacaomanutencao-e-instrumentacao-de-barra gens/view>. Acesso em: 08 mar. 2019.

AGÊNCIA NACIONAL DE ÁGUAS. Plano de Segurança da Barragem. Disponível em: <www2.ana.gov.br/Paginas/servicos/cadastros/Barragens/PlanoSeguranca.aspx>.Acesso em: 08 mar. 2019.

AGÊNCIA NACIONAL DE ÁGUAS. Relatório de Segurança de Barragens 2017. Disponível em: <www.snisb.gov.br/portal/snisb/relatorio-anual-de-seguranca-de-barragem/2017/rsb-2017-versaoenviada-ao-cnrh.pdf > . Acesso em: 08 mar.2019.

AGÊNCIA NACIONAL DE MINERAÇÃO. Plano de Segurança de Barragens. Disponível em: $<$ http://www.anm.gov.br/assuntos/barragens/pasta-classificacao-de-barragens-de-mineracao/plano-de-seguranca-debarragens>. Acesso em:15 out. 2019.

AGÊNCIA NACIONAL DE MINERAÇÃO. Relatório de Gestão do Exercício de 2017. Disponível em: <http://www.anm.gov.br/acesso-a-informacao/prestacao-de-contas/prestacao-de-contas-pdf/relatorio-de-gestaoexercicio-2017/view>. Acesso em: 13 out. 2019.

AGÊNCIA SENADO. Especialistas apontam que segurança de barragens depende de instrumentos legais e recursos. Disponível em:<www12.senado.leg.br/noticias/materias/2018/11/22/especialistas-apontam-que-segurancade-barragens-depende-de-instrumentos-legais-e-recursos >. Acesso em: 01 mar. 2019.

ANDERÁOS, A.; ARAÚJO, L. M. N.; NUNES, C. M. Classificação de barragem quanto à categoria de risco e dano potencial associado - um exercício. <arquivos.ana.gov.br/imprensa/noticias/20131119_PAP012965_04.pdf>. Acesso em: 02 mar. 2019.

ARCOVERDE, W. L. Atualização das medidas de implantação da Política Nacional de Segurança de Barragens PNSB no setor mineral brasileiro: novas medidas em segurança de barragens. Disponível em: <www.energia.sp.gov.br/wp- con- tent/uploads/2018/03/Walter-Lins.pdf >. Acesso em: 28 fev. 2019.

BOWKER , LINDSAY N; CHAMBERS , DAVID M. The RISK, PUBLIC LIABILITY, \& ECONOMICS of
TAILINGS
STORAGE em:<file:///C:/Users/ATENDIMENTO/Downloads/BowkerChambers-Risk-PublicLiability

EconomicsofTailingsStorageFacilityFailures23Jul15.pdf>. Acesso em: 20 mai. 2019.

BRASIL. LEI $\mathbf{N}^{\circ}$ 12.334, de 20 DE SETEMBRO DE 2010. Estabelece a Política Na- cional de Segurança de Barragens destinadas à acumulação de água para quaisquer usos, à disposição final ou temporária de rejeitos e à acumulação de resíduos industriais, cria o Sistema Nacional de Informações sobre Segurança de Barragens e altera a redação do art. 35 da Lei n o 9.433, de 8 de janeiro de 1997, e do art. 4 o da Lei n o 9.984, de 17 de julho de 2000. Diário Oficial da Re-pública Federativa do Brasil. Brasília, DF, 20 set. 2010. Disponível em:

< www.defesacivil.pr.gov.br/arquivos/File/Barragens/L12334.pdf >. Acesso em: 08 mar. 2019.

COSTA, Walter Duarte. Geologia de barragens. Oficina de Textos, 2016.

DA CRUZ, PAULO TEIXEIRA. 100 BARRAGENS BRASILEIRAS: CASOS HISTÓRICOS, MATERIAIS DE CONSTRUÇÃ O, PROJETO. OFICINA DE TEXTOS, 1996.

DAVIES, MICHAEL; MARTIN, TOOD. Mining market cycles and tailings dam incidents. In: 13th International Conference on Tailings and Mine Waste, Banff, AB. Disponível em: $<$ docplayer.net/14797608-Mining-marketcycles-and-tailings-dam-incidents.html.> . Acesso em: ago. 2019. 
DEPARTAMENTO NACIONAL DE PRODUÇÃO MINERAL.Guia rápido sobre Planos de Segurança de

Barragens. Disponível em: <www.defesacivil.pr.gov.br/arquivos/File/Barragens/Guia_empreendedor/guia_ra pido_de_ba rragens.pdf>. Acesso em: 01 mar 2019.

DIFIS/DNPM; CRUZ, J. S.; NEVES, L. P. Segurança de barragens. Disponível em: <www.ibram.org.br/sites/1300/1382/00005316.pdf >. Acesso em: 01 mar. 2019.

FEITOSA, ARnAldo B. Riscos e o estado atual da Política Nacional de Segurança Barragens. Disponivel em: <www.terra.com.br/noticias/dino/riscos-e-o-estado-atual-da-politica-nacional-de-seguranca-de barragens,997bb6223b4cdb76e0caa6e099644bb23jvea90s.html>. Acesso em 20 mai. 2019.

KOCHEN, ROBERTO. Monitoramento e segurança de barragens. Disponível em: $<$ https://www.institutodeengenharia.org.br/site/wp-content/uploads/2019/03/3-Monitoramento-eSeguran\%C3\%A7ade-Barrangens-IE-2019.pdf $>$. Acesso em: 20 mai. 2019.

KRÜGER, JOEL. Engenharia, espinha dorsal para o desenvolvimento humano. Disponível em: <www.creamg.org.br/index.php/comunicacao/noticias/2019/129-janeiro/960-engenharia-a-espinha-dorsal-para-o desenvolvimento-humano >. Acesso em: 03 mar. 2019.

LAMEGO, LEONARDO P.; DEZOLT, ELISA R. Artigo Segurança de Barragens. Disponível em: < http://www.azevedosette.com.br/anexos/20160222102840.pdf >. Acesso em: 28 abr. 2019.

MEDEIROS, CARLOS HENRIQUE. Segurança de barragens e Avaliação de Riscos - Seminário Nacional. Disponível em: <http://cbdb.org.br/xxxsngb/download/trabalhos_temas/1205/tarde/Carlos\%20Henrique/XXX\% 20S NGB-PAINELISTA\%20CARLOS\%20HENRIQUE\%2014HRS.pdf>. Acesso em: 24 mai. 2019.

MILANEZ, BRUNO; WANDERLEY, LUIZ; MANSUR; MAÍRA. A questão mineral no Brasil - Vol.2 ANTES FOSSE MAIS LEVE A CARGA: Reflexões sobre o desastre da Samarco/ Vale / BHP Billiton. Disponível em: <http://www.ufff.br/poemas/files/2016/11/Livro-Completo-com-capa.pdf>. Acesso em: 25 mai. 2019.

SIMONATO, THIAGO CAVALCANTE; MAGALHÃES, ALINE SOUZA. Desastres urbanos e a conjuntura econômica: caso de Mariana-MG. <http://anais.anpur.org.br/index.php/anaisenanpur/article/view/2360/2339>. Acesso em: 14 out. 2019.

SOBRINHO, WANDERLEY PREITE. Minas Gerais tem um rompimento de barragem a cada 2 anos, diz estudo. Disponível em: <https://noticias.uol.com.br/cotidiano/ultimas- noticias/2019/01/28/minas-gerais-temum-rompimento-de-barragem-a-cada-2-anos-diz- pesquisa.htm >. Acesso em: 05 abr.2019. 